\title{
Hospitalizations for Osteoporosis-Related Fractures: Analysis from Eastern Saudi Arabia
}

\author{
Mir Sadat-Ali*, AbdulAziz H. Al-Shamsi, Zainab R. Al Ghanim, Khaleel I. Al Batran, \\ Yousef M. Al Jamaan, Abrar S. Hashishi, Faisal M. Al Anazi, Abdul Raheem A. Al Talib, \\ Fatima Abdulmohsen Mohamed
}

The Department of Orthopaedic Surgery, King Fahd Hospital of the University, Imam Abdul Rahman Bin Faisal University, Al Khobar, KSA

Email: *drsadat@hotmail.com, smali@iau.edu.sa

How to cite this paper: Sadat-Ali, M., Al-Shamsi, A.H., Al Ghanim, Z.R., Al Batran, K.I., Al Jamaan, Y.M., Hashishi, A.S., Al Anazi, F.M., Al Talib, A.R.A. and Mohamed, F.A. (2020) Hospitalizations for Osteoporosis-Related Fractures: Analysis from Eastern Saudi Arabia. Open Journal of Orthopedics, 10, 117-123.

https://doi.org/10.4236/ojo.2020.106013

Received: April 23, 2020

Accepted: May 30, 2020

Published: June 2, 2020

Copyright $\odot 2020$ by author(s) and Scientific Research Publishing Inc. This work is licensed under the Creative Commons Attribution International License (CC BY 4.0).

http://creativecommons.org/licenses/by/4.0/

\begin{abstract}
Background and Objectives: Osteoporosis causes fragility fractures which increase the morbidity and mortality in the elderly. Our objective was to look at the hospital admissions due to fragility fractures and site of fractures. Methods: This is a retrospective study of a 2-year period (2017-2018), in which we evaluated all the admissions of fragility fractures at King Fahd Hospital of the University, Al Khobar, Saudi Arabia. A Fragility Fracture is a fracture which occurs in patients with low bone mass due to a fall from a standing height. The data were gathered from the Quadru Med patient care system for patients over the age of 50 years: sex, site of fracture, previous fractures, and treatment meted out. The hospitalization rate for fragility fractures was calculated by taking into consideration of all the adult admissions to the orthopaedic department. Ethical approval was obtained from the Institutional Review Board of the Hospital and the Imam Abdul Rahman Bin Faisal University, Dammam. Results: During the study period 187 patients with fragility fractures were admitted. The mean age was $68.55 \pm 12.43$ years; fracture femur was the most common with 136 (72.7\%), tibia $15(8 \%)$ and spine 14 (7.5\%). At the time of discharge based on the T score of spine 50 were osteopenic and 45 were osteoporotic. Overall adult admission for the study period was 1410 patients and $13.26 \%$ were patients with fragility fractures. There were $3(1.6 \%)$ deaths within the first 30 days in the hospital. Conclusions: Fracture femur was the most common fragility fracture seen in our study. Orthopaedic surgeons should be ready to treat all fragility fractures and treat osteoporosis appropriately so that a second fracture is prevented.
\end{abstract}

\section{Keywords}

Fragility Fractures, Saudi Arabia, Osteopenia, Osteoporosis 


\section{Introduction}

Osteoporosis is a clinical syndrome of loss of bone, and deterioration of the micro-architectural structure of the bone leading to fractures with minimal trauma. The prevalence of osteoporosis among Saudi Arabians is reported to be in the range of $30 \%-35 \%$ [1] [2] [3] [4] and the incidence of fracture femur rose from $2.91 / 1000$ to $6 / 1000$ in a decade [5] [6] [7]. Recent study has shown the overall cost of treating osteoporosis related femur fractures is Saudi Riyals 564.75 million yearly as direct costs and the yearly total cost goes up to 2.359 billion Saudi riyals [7]. Still many patients with osteoporosis in Saudi Arabia are neither diagnosed nor treated which could increase the incidence of osteoporosis related fractures and a fragility fracture is the first indication of osteoporosis.

It has been proved beyond doubt that osteoporosis enhances the risk of fractures [8] and only the prevalence of hip and vertebral fractures have been sporadically reported from Saudi Arabia. The prevalence of vertebral fractures in the men is reported to be $13.1 \%$ and in women it was found to be 20.3\% [9] [10]. Apart from hip and vertebral fractures, there is no data from Saudi Arabia of the other fragility fractures like wrist, humerus and forearm which predicts subsequent hip fractures [11] [12]. It was found that a prior proximal humeral fracture could increase by over 5 times for a risk of hip fracture within the 12 months period [13].

Our objective was to look retrospectively at all admissions with fragility fractures and site of fractures in Saudi Arabian citizens at our center.

\section{Methods}

This retrospective study for the 2-year period between 2017-2018, at the tertiary care King Fahd Hospital of the University Al Khobar, Saudi Arabia was conducted. We evaluated all the admissions of all fractures, which occurred due to fall from ground level (Fragility Fracture). The data was gathered from the QuadruMed patient care system for patients over the age of 50 years, sex, site of fracture, previous fractures, treatment meted out. Patients were stratified into 50 - 60, $61-70,71-80$ and $>81$ years or older. The hospitalization rate for fragility fractures was calculated by taking into consideration of all the adult admissions to the orthopaedic department. Ethical approval was obtained from the Institutional Review Board of the Hospital and the Imam Abdul Rahman Bin Faisal University, Dammam.

The data was entered in the database and analyzed using SPSS Inc. version 21. The data were expressed as mean \pm SD. Statistically significant differences between the different groups were determined with the Student's t-test using a ratio of $\mathrm{P}<0.05$, which is considered to be significant, and was ascertained at a CI of $95 \%$.

\section{Results}

During the study period 187 patients with fragility fractures were admitted. The 
mean age was $68.55 \pm 12.43$ years (Range 50 - 95). Ninety-one were males and 96 were females. Table 1 gives the demographic data of all patients. One-third 58 (31.1\%) were below the age of 60 years. Fracture femur was the most common with 136 (72.7\%), Tibia 15 (8\%) and Spine 14 (7.5\%). Figure 1 gives the comparison between the male and female patients and different fractures. Table 2 shows the fracture pattern in male and versus female patients. In men 73 (80.2\%) patients had femur fracture while 57 (59.4\%) of women had femur fracture which was statistically significant $\mathrm{P}<0.001$. Fracture of the humerus, Tibia and pelvis was more common in women than in men which significant at $\mathrm{P}$ of $<0.04$, $<0.001$ and $<0.04$. Only $32(17.11 \%)$ of patients were on osteoporotic treatment at the time of the fragility fracture. Of the 187 patients $160(85.5 \%)$ were not on appropriate treatment for osteoporosis (Antiresorptives or Anabolics). Seventeen $(62.9 \%)$ were on Bisphosphonates and 10 (37.1\%) were on anabolic agent. Seventy-six patients had a DXA scan available for analysis. Table 3 gives the details of the T score of the hip and lumbar spine of patients. Overall adult admission for the study period was 1410 patients and $13.26 \%$ were patients with fragility fractures. There were $3(1.6 \%)$ deaths within the first 30 days in the hospital.

Table 1. Demographic data of all patients admitted with fragility fractures.

\begin{tabular}{cccc}
\hline Age Group in Years & Male (91) & Female (96) & Total \\
\hline $50-60$ & 31 & 27 & $58(31 \%)$ \\
$61-70$ & 19 & 25 & $44(23.5 \%)$ \\
$71-80$ & 23 & 24 & $47(25.1 \%)$ \\
$\geq 81$ & 18 & 20 & $38(20.4 \%)$ \\
\hline
\end{tabular}

Table 2. Fracture pattern between male and female patients.

\begin{tabular}{cccc}
\hline Site of Fracture & Male (91) & Female (96) & P Value \\
\hline Femur Neck & 30 & 25 & 0.18 \\
Intertrochanteric & 25 & 24 & 0.8 \\
Subtrochanteric & 10 & 5 & 0.09 \\
Shaft femur & 8 & 4 & 0.1 \\
Distal Femur & 1 & 4 & 0.002 \\
Vertebral & 6 & 8 & 0.2 \\
Radius & 3 & 3 & 0.1 \\
Humerus & 4 & 8 & 0.04 \\
Tibia & 3 & 12 & 0.001 \\
Pelvis & 1 & 3 & 0.04 \\
\hline
\end{tabular}

Table 3. T score of hip and lumbar spine of 76 patients.

\begin{tabular}{ccc}
\hline Hip & Osteopenia (50) & Osteoporosis (26) \\
& $-1.345 \pm 0.7$ & $-3.27 \pm 0.425$ \\
Spine & Osteopenia (31) & Osteoporosis (45) \\
& $-1.76 \pm 0.6$ & -3.00 \\
\hline
\end{tabular}




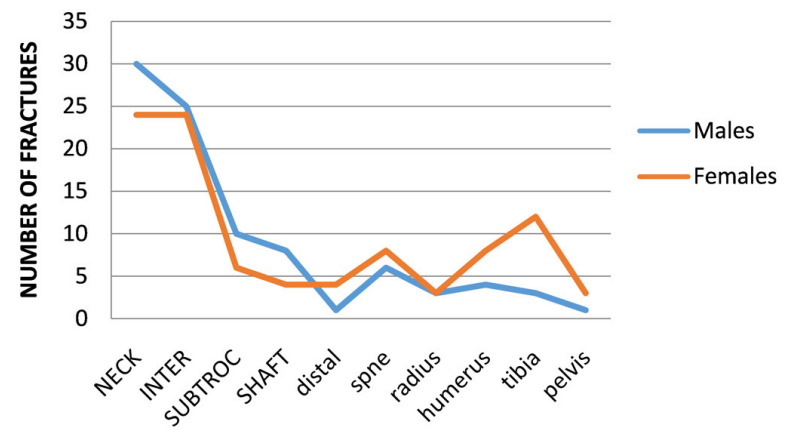

Figure 1. Comparison between different fragility fractures in males and females.

\section{Discussion}

Our study shows that hip fractures are still the most common fragility fractures seen in our country with $72.7 \%$ of all fragility fractures; secondly the age at which these fractures occurred in this study was younger than reported in other countries. The reported mean age for fragility femoral fractures is between 75 80 years [14]. In this study the average age was 68.5 years. Secondly we observed that pattern of other fragility fractures requiring admission was different than reported elsewhere. The distal radius and proximal humerus fractures were the most common reported apart from femur in elderly due to osteoporosis [15] [16]. Melton et al. (1992) [17] reported that $16 \%$ in women and 5\% in men, and in Sweden it was $20.8 \%$ and $4.6 \%$ in women and men [18]. In our patients fractures of the distal radius were quite low of $3.2 \%$. This could be our limitation that we only considered the admissions and other acceptable cases of distal radius fractures could have been manipulated, reduced and discharged in cast from emergency room.

Osteoporotic fractures are generally classified as vertebral or non-vertebral. Orthopaedic surgeons concentrate more on Non-Vertebral like hip, wrist and humerus neglecting other fractures which could be related to osteoporosis. An expert panel in United States suggested that apart from hip fractures, forearm fractures of the tibia and fibula, patella, ribs, and pelvis are fragility fractures related to osteoporosis [19]. Reports of osteoporosis related diaphyseal fractures of the tibia in the literature are limited. In our study the prevalence of fractures of tibia/fibula was higher than that of vertebral fracture requiring admission. Tibial fractures accounted for 15 (8\%) compared to that of the vertebral column of 14 (7.5\%). We believe that patients who are $\geq 50$ years of age and fell from the ground level and sustain tibial fractures should be properly investigated and treated for osteoporosis.

This study has some limitations that it was not possible to analyze all fragility fractures which came through the emergency room and we analyzed only hospitalized fractures but we believe our sample is representative one which could at least give a cue for other researchers to conduct studies including emergency room patients; otherwise there will concern potential underestimation of such fractures. The importance of this study is that it has given different type of fragility 
fractures seen in the Middle Eastern society and the prevalence, which will help orthopaedic surgeons to investigate every fracture in patients over the age of 50 years.

In conclusion based on this 2-year study we found that fragility fractures are occurring at a younger age and fracture femur is the most common fragility fractures in our society and in $28 \%$ fractures occur at other sites such as Tibia and fibula $15(8 \%)$ and spine 14 (7.5\%). Our results confirm that fragility fractures occupy about $14 \%$ of all hospital admissions raising serious concerns for Ministry of health the largest stakeholder that provides free treatment to all citizens to implement appropriate strategies in the early diagnosis, and appropriate treatment and prevent all fragility fractures.

\section{Acknowledgements}

None.

\section{Statement of Ethics}

The study was conducted after approval of the Institutional Review and Ethical Board of the Imam Abdulrahman Bin Faisal University, Dammam and guidelines for human studies were followed including written informed consent was obtained.

\section{Disclosure Statement}

All authors declare that there is no conflict of interests related to this study and did not receive any forms of support and financial involvement (e.g. employment, consultancies, honoraria, stock ownership and options, expert testimony, grants or patents received or pending, royalties) in the last three years.

\section{Funding Sources}

There was no funding for this study.

\section{Author's Contributions}

Study conception and design: Sadat-Ali, Dr Abdulraheeem A Al Talib.

Acquisition of data: Dr Abdulraheeem A Al Talib, Dr Abdul Aziz H Al-Shamsi, Dr Zainab R Al Ghanim, Dr Zainab R Al Ghanim.

Analysis and interpretation of data: Dr Yousef M Al Jamaan, Sadat-Ali, Dr Abrar S Hashishi.

Drafting of manuscript: Dr Faisal M Al Anazi, Dr Yousef M Al Jamaan, Sadat-Ali.

Critical revision: Sadat-Ali, Dr Abdul Aziz H Al-Shamsi, Dr Zainab R Al Ghanim.

\section{Conflicts of Interest}

The authors declare no conflicts of interest regarding the publication of this paper. 


\section{References}

[1] Sadat-Al, M., Al-Habdan, I. and Marwah, S. (1996) Bone Mineral Density Measurements of Distal Radius in Saudi Arabian Females. Annals of Saudi Medicine, 16, 414-416. https://doi.org/10.5144/0256-4947.1996.414

[2] Al-Habdan, I.M., Sadat-Ali, M., Al-Muhanna, F.A., Al-Elq, A.H. and Al-Mulhim, A.A. (2009) Bone Mass Measurement Using Quantitative Ultrasound in Healthy Saudi Women. A Cross-Sectional Screening. Saudi Medical Journal, 30, 1426-1431.

[3] El-Desouki, M.I. (2003) Osteoporosis in Postmenopausal Saudi Women Using Dual X-Ray Bone Densitometry. Saudi Medical Journal, 24, 953-956.

[4] Ardawi, M.S., Maimany, A.A., Bahksh, T.M., Nasrat, H.A., Milaat, W.A. and Al-Raddadi, R.M. (2005) Bone Mineral Density of the Spine and Femur in Healthy Saudis. Osteoporosis International, 16, 43-55. https://doi.org/10.1007/s00198-004-1639-9

[5] Bubshait, D. and Sadat-Ali, M. (2007) Economic Implications of Osteoporosis-Related Femoral Fractures in Saudi Arabian Society. Calcified Tissue International, 81, 455-458. https://doi.org/10.1007/s00223-007-9090-5

[6] al-Nuaim, A.R., Kremli, M., al-Nuaim, M. and Sandkgi, S. (1995) Incidence of Proximal Femur Fracture in an Urbanized Community in Saudi Arabia. Calcified Tissue International, 56, 536-538. https://doi.org/10.1007/BF00298585

[7] Sadat-Ali, M., Al-Dakheel, D.A., Azam, M.Q., Al-Bluwi, M.T., Al-Farhan, M.F., Amer, H., et al. (2015) Reassessment of Osteoporosis-Related Femoral Fractures and Economic Burden in Saudi Arabia. Archives of Osteoporosis, 10, 37. https://doi.org/10.1007/s11657-015-0240-5

[8] Riggs, B.L. and Melton, L.J. (1995) The Worldwide Problem of Osteoporosis: Insights Afforded by Epidemiology. Bone, 17, 505S-511S.

https://doi.org/10.1016/8756-3282(95)00258-4

[9] Sadat-Ali, M., Gullenpet, A.H., Al-Turki, H.A., Abdulrahman, T.W., Al-Elq, A.H., Azzam, M.Q., et al. (2011) Are We Missing Osteoporosis-Related Vertebral Fractures in Men? Asian Spine Journal, 5, 107-110.

https://doi.org/10.4184/asj.2011.5.2.107

[10] Sadat-Ali, M., Gullenpet, A.H., Al-Mulhim, F., Al Turki, H., Al-Shammary, H., Al-Elq, A., et al. (2009) Osteoporosis-Related Vertebral Fractures in Postmenopausal Women: Prevalence in a Saudi Arabian Sample. Eastern Mediterranean Health Journal, 15, 1420-1425.

[11] Cummings, S.R. and Melton, L.J. (2002) Epidemiology and Outcomes of Osteoporotic Fractures. The Lancet, 359, 1761-1767. https://doi.org/10.1016/S0140-6736(02)08657-9

[12] Klotzbuecher, C.M., Ross, P.D., Landsman, P.B., Abbott, T.A. and Berger, M. (2000) Patients with Prior Fractures Have an Increased Risk of Future Fractures: A Summary of the Literature and Statistical Synthesis. Journal of Bone and Mineral Research, 15, 721-739. https://doi.org/10.1359/jbmr.2000.15.4.721

[13] Clinton, J. (2009) Proximal Humeral Fracture as a Risk Factor for Subsequent Hip Fractures. The Journal of Bone and Joint Surgery. American Volume, 91, 503-511. https://doi.org/10.2106/JBJS.G.01529

[14] Tsuda, T. (2017) Epidemiology of Fragility Fractures and Fall Prevention in the Elderly: A Systematic Review of the Literature. Current Orthopaedic Practice, 28, 580-585. https://doi.org/10.1097/BCO.0000000000000563

[15] Kelsey, J.L., Browner, W.S., Seeley, D.G., et al. (1992) Risk Factors for Fractures of 
the Distal Forearm and Proximal Humerus. The Study of Osteoporotic Fractures Research Group. American Journal of Epidemiology, 135, 477-489.

https://doi.org/10.1093/oxfordjournals.aje.a116314

[16] O’Neill, T.W., Marsden, D., Adams, J.E., et al. (1996) Risk Factors, Falls, and Fracture of the Distal Forearm in Manchester, UK. Journal of Epidemiology and Community Health, 50, 288-292. https://doi.org/10.1136/jech.50.3.288

[17] Melton, L.J. III, Chriscilles, E.A., Cooper, C., Lane, A.W. and Riggs, B.L. (1992) Perspective: How Many Women Have Osteoporosis? Journal of Bone and Mineral Research, 7, 1005-1010. https://doi.org/10.1002/jbmr.5650070902

[18] Van Staa, T.P., Dennison, E.M., Leufkens, H.G. and Cooper, C. (2001) Epidemiology of Fractures in England and Wales. Bone, 29, 517-522. https://doi.org/10.1016/S8756-3282(01)00614-7

[19] Warriner, A.H., Patkar, N.M., Curtis, J.R., Delzell, E., Gary, L., Kilgore, M., et al. (2011) Which Fractures Are Most Attributable to Osteoporosis? Journal of Clinical Epidemiology, 64, 46-53. https://doi.org/10.1016/j.jclinepi.2010.07.007 